University of Wollongong

Research Online

Australian Institute for Innovative Materials -

Papers

Australian Institute for Innovative Materials

$1-1-2019$

Exfoliation of amorphous phthalocyanine conjugated polymers into ultrathin nanosheets for highly efficient oxygen reduction

Wenping Liu

Chiming Wang

Lijie Zhang

Houhe Pan

Wenbo Liu

w1949@uowmail.edu.au

See next page for additional authors

Follow this and additional works at: https://ro.uow.edu.au/aiimpapers

Part of the Engineering Commons, and the Physical Sciences and Mathematics Commons

Research Online is the open access institutional repository for the University of Wollongong. For further information contact the UOW Library: research-pubs@uow.edu.au 


\title{
Exfoliation of amorphous phthalocyanine conjugated polymers into ultrathin nanosheets for highly efficient oxygen reduction
}

\begin{abstract}
It is a significant challenge to develop a high-efficiency synthetic methodology to access fully conjugated 2D conjugated polymer (CP)/covalent organic framework (COF) nanosheets (NSs) that have great application potential for electronics and energy. Herein, we report the exfoliation of a series of amorphous ethynyl-linked phthalocyanine (Pc) CPs (MPc-CPs, M = Fe, Co, Fe0.5Co0.5) into ultrathin MPc-CP NSs.

Random coupling between the four regioisomers (with D4h, D2h, C2v and Cs symmetry) of the two tetra$\beta$-substituted phthalocyanine precursors endows the resulting phthalocyanine conjugated polymers MPcCPs with intrinsic structural defects and a disordered framework on individual layers. This in turn induces a diminished interlayer overlapping and a weakened interlayer $\pi-\pi$ stacking interaction, facilitating the possible exfoliation of MPc-CPs into ultrathin 2D NSs with a yield of over $50 \%$. The direction observation by transmission electron microscopy (TEM) and atomic force microscopy (AFM) demonstrates that the ultrathin MPc-CP NSs possess a smooth surface with a uniform thickness of 1-3 nm and a lateral size of hundreds of nanometers. The as-prepared bimetallic Fe0.5Co0.5Pc-CP NSs were further used to fabricate a heterostructure Fe0.5Co0.5Pc-CP NS@G with graphene NSs as an oxygen reduction reaction (ORR) catalyst, which exhibits an onset potential of $1006 \mathrm{mV}$ and a half-wave potential of $927 \mathrm{mV}$ in $0.1 \mathrm{M} \mathrm{KOH}$, representing one of the best values in an alkaline medium. Moreover, the excellent ORR activity of the exfoliated tetrapyrrole-based conjugated NSs hybridized with graphene has also been demonstrated by a $\mathrm{Zn}$-air battery device, showing an open circuit voltage of $1.34 \mathrm{~V}$ and a peak power density of ca. $180 \mathrm{~mW}$ $\mathrm{cm}-2$.
\end{abstract}

\section{Keywords}

nanosheets, ultrathin, into, polymers, conjugated, phthalocyanine, amorphous, reduction, exfoliation, oxygen, efficient, highly

\section{Disciplines}

Engineering | Physical Sciences and Mathematics

\section{Publication Details}

Liu, W., Wang, C., Zhang, L., Pan, H., Liu, W., Chen, J., Yang, D., Xiang, Y., Wang, K., Jiang, J. \& Yao, X. (2019). Exfoliation of amorphous phthalocyanine conjugated polymers into ultrathin nanosheets for highly efficient oxygen reduction. Journal of Materials Chemistry A, (7), 3112-3119.

\section{Authors}

Wenping Liu, Chiming Wang, Lijie Zhang, Houhe Pan, Wenbo Liu, Jun Chen, Dongjiang Yang, Yanjuan Xiang, Kang Wang, Jianzhuang Jiang, and Xiangdong Yao 
Received 18th November 2018 Accepted 14th January 2019

\title{
Exfoliation of amorphous phthalocyanine conjugated polymers into ultrathin nanosheets for highly efficient oxygen reduction $†$
}

\author{
Wenping Liu, ${ }^{a}$ Chiming Wang, ${ }^{a}$ Lijie Zhang, ${ }^{d}$ Houhe Pan, ${ }^{a}$ Wenbo Liu, ${ }^{a}$ Jun Chen, ${ }^{c}$ \\ Dongjiang Yang, (D) ${ }^{d}$ Yanjuan Xiang, ${ }^{e}$ Kang Wang, ${ }^{* a b}$ Jianzhuang Jiang (D) *a \\ and Xiangdong Yao
}

\begin{abstract}
It is a significant challenge to develop a high-efficiency synthetic methodology to access fully conjugated 2D conjugated polymer (CP)/covalent organic framework (COF) nanosheets (NSs) that have great application potential for electronics and energy. Herein, we report the exfoliation of a series of amorphous ethynyl-linked phthalocyanine (Pc) CPs (MPc-CPs, M 1/4 Fe, Co, $\mathrm{Fe}_{0.5} \mathrm{Co}_{0.5}$ ) into ultrathin MPc-CP NSs. Random coupling between the four regioisomers (with $D_{4 \mathrm{~h}}, D_{2 \mathrm{~h}}, C_{2 \mathrm{v}}$ and $C_{\mathrm{s}}$ symmetry) of the two tetra-b-substituted phthalocyanine precursors endows the resulting phthalocyanine conjugated polymers MPc-CPs with intrinsic structural defects and a disordered framework on individual layers. This in turn induces a diminished interlayer overlapping and a weakened interlayer $p-p$ stacking interaction, facilitating the possible exfoliation of MPc-CPs into ultrathin 2D NSs with a yield of over $50 \%$. The direction observation by transmission electron microscopy (TEM) and atomic force microscopy (AFM) demonstrates that the ultrathin MPc-CP NSs possess a smooth surface with a uniform thickness of 1$3 \mathrm{~nm}$ and a lateral size of hundreds of nanometers. The as-prepared bimetallic $\mathrm{Fe}_{0.5} \mathrm{Co}_{0.5} \mathrm{Pc}_{\mathrm{C}} \mathrm{CP} \mathrm{NSs}$ were further used to fabricate a heterostructure $\mathrm{Fe}_{0.5} \mathrm{Co}_{0.5} \mathrm{Pc}-\mathrm{CP} \mathrm{NS} @ \mathrm{G}$ with graphene NSs as an oxygen reduction reaction (ORR) catalyst, which exhibits an onset potential of $1006 \mathrm{mV}$ and a half-wave potential of $927 \mathrm{mV}$ in $0.1 \mathrm{M} \mathrm{KOH}$, representing one of the best values in an alkaline medium. Moreover, the excellent ORR activity of the exfoliated tetrapyrrole-based conjugated NSs hybridized with graphene has also been demonstrated by a $\mathrm{Zn}$-air battery device, showing an open circuit voltage of $1.34 \mathrm{~V}$ and a peak power density of ca. $180 \mathrm{~mW} \mathrm{~cm}^{-2}$.
\end{abstract}

\section{Introduction}

Inspired by the discovery and prosperity of graphene, arti $\square$ cial two-dimensional (2D) organic conjugated layered materials with an extended $\mathrm{p}$ system, such as graphdiyne, 2D organic conjugated polymers (CPs), and 2D covalent organic

\footnotetext{
${ }^{a}$ Beijing Key Laboratory for Science and Application of Functional Molecular and Crystalline Materials, Department of Chemistry, University of Science and Technology Beijing, Beijing 100083, China. E-mail: kangwang@ustb.edu.cn; jianzhuang@ustb.edu.cn

${ }^{b}$ Queensland Micro- and Nanotechnology Centre, Griffith University, Nathan Campus, QLD 4111, Australia.E-mail: x.yao@griffith.edu.au

${ }^{c}$ ARC Centre of Excellence for Electrmaterials Science, Intelligent Polymer Research Institute, Australian Institute for Innovative Materials, Innovation Campus, University of Wollongong, North Wollongong, NSW 2519, Australia

"Collaborative Innovation Center for Marine Biomass Fibers, Materials and Textiles of Shandong Province, College of Chemical and Environmental Engineering, Qingdao University, Qingdao 266071, China

'State Key Laboratory of Catalytic Material and Reaction Engineering, Research Institute of Petroleum Processing, SINOPEC, Beijing 100083, China

†Electronic supplementary information (ESI) available. See DOI: $10.1039 / \mathrm{c} 8 \mathrm{ta} 11044 \mathrm{a}$
}

frameworks (COFs), ${ }^{1-10}$ have received great research interest. Owing to bottom-up approaches, the structures and components of such 2D polymers could be rationally designed and modulated at the atomic or molecular level, which will offer the desirable properties and functions with a wide range of applications in gas storage and separation, ${ }^{11,12}$ catalysis, ${ }^{13-16}$ sensors, ${ }^{17,18}$ and electronic devices. ${ }^{19-21}$ Recently, 2D conjugated $\mathrm{CP} / \mathrm{COF}$ nanosheets (NSs) with a few atomic layers have emerged as a new member in the 2D nanomaterial family and attracted increasing attention. ${ }^{22-26}$ Compared to bulk $\mathrm{CP} / \mathrm{COF}$ materials, 2D CP/COF nanosheets have unique superiorities. For instance, their larger surface area and more accessible active sites on the surfaces facilitate the contact with substrate molecules under a lower diffusion barrier, and thus enhance the performance of $2 \mathrm{D} \mathrm{CP} / \mathrm{COF}$ nanosheets in catalysis and sensing applications..$^{27-30}$ Additionally, the ultrathin structure would enable the formation of stable dispersions of the $2 \mathrm{D} \mathrm{CP} / \mathrm{COF}$ nanosheets, and thus would enable large-area and low-cost liquid-deposition techniques, such as the quasi-Langmuir-Shäfe method, spin coating, or inkjet printing. ${ }^{31-34}$ 
Generally, 2D CP/COF NSs are prepared by exfoliating their bulk counterparts by solvent-assisted liquid sonication, ${ }^{35,36}$ mechanical delamination, ${ }^{37}$ self-exfoliation, ${ }^{38}$ or sequential post-synthetic modi $\square$ cation. ${ }^{39}$ However, because of the strong interlayer $p-p$ interactions, the exfoliation yield of most obtained 2D CP/COF NSs is usually quite low. Recently, it has been reported that introduction of a cycloaddition reaction, twist, or $\square$ exible building units within the COF backbone is able to destroy/weaken the interlayer $p-p$ interaction, leading to easier exfoliation of the bulk COF precursors into ultrathin NSs. ${ }^{30,40,41}$ However, the desired extended $p$ conjugated structure was simultaneously destroyed/weakened by the aforementioned strategies, which may result in low electron transfer capability and thus limit their applications in electronics and energyrelated $\square$ elds. Therefore, a new methodology still needs to be established to develop a high-efficiency synthetic methodology to access 2D CP/COFNSs.

Herein, we report a general approach to fabricate a series of ultrathin 2D CP NSs (MPc-CP NSs, $\mathrm{M} 1 / 4 \mathrm{Fe}_{0.5} \mathrm{Co}_{0.5}, \mathrm{Fe}$, and $\mathrm{Co}$ ) with a fully conjugated electronic structure, which was exfoliated from ethynyl-linked phthalocyanine (Pc) CPs prepared from phthalocyanine monomers, $\mathrm{M}\left[\mathrm{Pc}(\mathrm{I})_{4}\right]$ and $\mathrm{M}\left[\mathrm{Pc}(\text { ethynyl })_{4}\right]$, through a Sonogashira-Hagihara coupling reaction. ${ }^{42}$ Owing to the fact that both the two tetra-b-substituted phthalocyanine precursors, M[Pc(I) ] and M[Pc(ethynyl) ], are composed of four

\section{4}

regioisomers (with $D_{4 \mathrm{~h}}, D_{2 \mathrm{~h}}, C_{2 \mathrm{v}}$ and $C_{\mathrm{s}}$ symmetry), ${ }^{43}$ the assynthesized CPs have a layered structure in which the layers are abundant with intrinsic structural defects and highly disordered framework nature. Such an amorphous structure of the individual layer with defects enables a diminished interlayer overlapping area and weakened interlayer $p-p$ stacking interactions, ${ }^{44,45}$ facilitating an easier and successful exfoliation of the bulk CP materials into ultrathin NSs with a high yield of over $50 \%$. Meanwhile, hetero-assemblies of 2D nanolayers such as transition metal dichalcogenides/diseleniums, ${ }^{46}$ layered double hydroxides, ${ }^{47}$ and metal-organic frameworks ${ }^{48}$ with various graphene NSs (including graphene, nitrogen doped graphene, and defective graphene) have been recently received increasing interest in fabricating versatile high performance electrocatalysts including oxygen reduction reaction (ORR), oxygen evolution reaction (OER), and hydrogen evolution reaction (HER) catalysts. The high activity is due to the combination of the highly exposed active centers presented on 2D nanolayers ${ }^{27-30}$ and high electron transfer capability of graphene $\mathrm{NSs}^{49-52}$ together with strong interaction between these components to reform the electronic distribution. Thanks to the ultrathin nature, the as-prepared bimetallic $\mathrm{Fe}_{0.5} \mathrm{Co}_{0.5} \mathrm{Pc}-\mathrm{CP}$ NSs were used to fabricate a heterostructure $\mathrm{Fe}_{0.5} \mathrm{Co} 0.5 \mathrm{Pc}-\mathrm{CP}$ NS@G with graphene NSs, which exhibits high ORR catalytic activity in an alkaline medium.

\section{Results and discussion}

\section{Synthesis and characterization of MPc-CP NSs}

Scheme 1a schematically illustrates the approach to fabricate ultrathin MPc-CP NSs. The bulk MPc-CP materials were prepared from corresponding $\mathrm{M}\left[\mathrm{Pc}\left(\mathrm{I}_{4}\right]_{4}\right.$ and $\mathrm{M}\left[\mathrm{Pc}(\text { ethynyl })_{4}\right]$ via

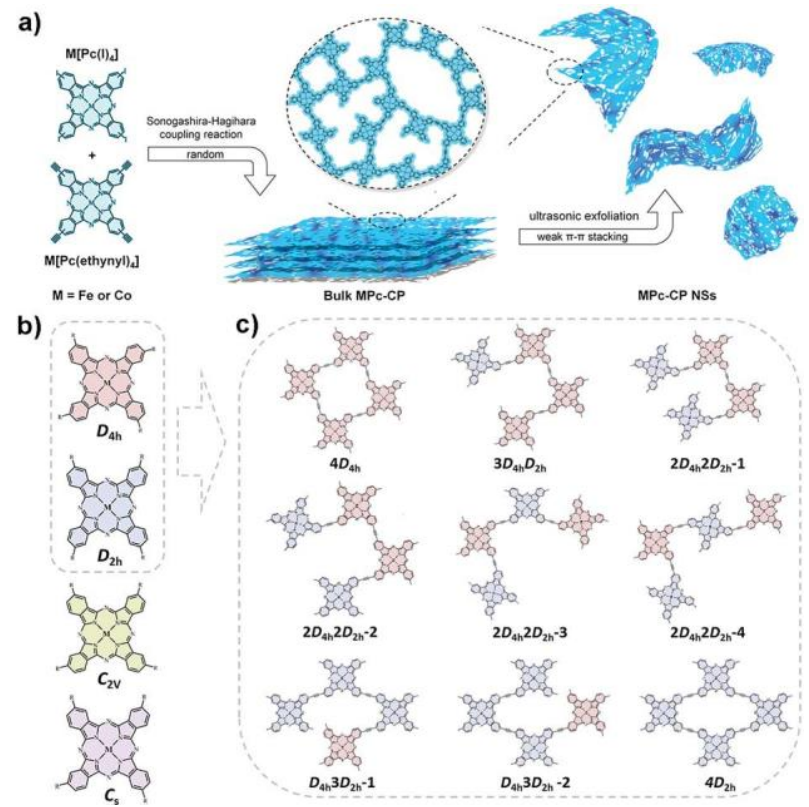

Scheme 1 (a) Synthesis of the phthalocyanine based CP NSs, MPc-CP NSs (M $1 / 4 \mathrm{Fe}, \mathrm{Co}$, and $\mathrm{Fe}_{0.5} \mathrm{Co}_{0.5}$ ). (b) The four kinds of isomers (with $D_{4 \mathrm{~h}}, D_{2 \mathrm{~h}}, C_{2 \mathrm{v}}$ and $C_{\mathrm{s}}$ symmetry) for tetra-b-substituted phthalocya- nines. (c) Nine quadrilateral structure models fabricated from four phthalocyanine molecules with $D_{4 \mathrm{~h}}$ or $D_{2 \mathrm{~h}}$ symmetry.

a Sonogashira-Hagihara coupling reaction according to a previously reported procedure. ${ }^{42}$ It is worth noting that both $\mathrm{M}$ $\left[\mathrm{Pc}\left(\mathrm{I}_{4}\right]\right.$ and $\mathrm{M}\left[\mathrm{Pc}(\text { ethynyl })_{4}\right]$ are tetra-b-substituted phthalocyanines, which are actually a mixture of four constitutional isomers (with $D_{4 \mathrm{~h}}, D_{2 \mathrm{~h}}, C_{2 \mathrm{v}}$ and $C_{\mathrm{s}}$ symmetry) (Scheme $1 \mathrm{~b}$ ). Random coupling between the four $\mathrm{M}\left[\mathrm{Pc}(\mathrm{I})_{4}\right]$ and $\mathrm{M}$ [Pc(ethynyl)4] isomers leads to the formation of MPc-CPs with a highly disordered individual layer. Scheme $1 \mathrm{c}$ shows a quadrilateral structure fabricated from four phthalocyanine molecules with $D_{4 \mathrm{~h}}$ or $D_{2 \mathrm{~h}}$ symmetry as an example to illustrate the disordered individual layer of MPc-CPs. As can be seen, nine structural models could be formed by a random combination of four phthalocyanine molecules with $D_{4 \mathrm{~h}}$ or $D_{2 \mathrm{~h}}$ symmetry. The $\mathrm{p}-\mathrm{p}$ interactions between the $4 \mathrm{D}_{4 \mathrm{~h}}$ model and the nine structural models were also investigated by DFT calculations. As can be seen in Fig. $\mathrm{S} 1$ in the ESI, $\uparrow$ the binding energy per phthalocyanine molecule between two different models is $27-81 \%$ lower than that between two $4 D_{4 \mathrm{~h}}$ models, owing to the reduced overlapping area. These results suggest that the MPc-CP individual layers fabricated from more phthalocyanine molecules with four kinds of symmetry are completely disordered and amorphous. As a result, the interlayer overlapping area would be further diminished, which weakens the interlayer $p-p$ stacking in the CPs, and in turn facilitates the possible exfoliation of the bulk MPc-CP materials into ultrathin 2D nanosheets by the subsequent solvent-assisted liquid sonication. With the bimetal counterparts $\mathrm{Fe}_{0 .} \mathrm{Co}_{0.5} \mathrm{Pc}-\mathrm{CP}$ NSs as representative, the yield of $\mathrm{Fe}_{0.5} \mathrm{Co} 0.5 \mathrm{Pc}-\mathrm{CP}$ NSs could be $c a .36 \%$ aler ultrasonic exfoliation for only $2 \mathrm{~h}$ in ethanol, with a maximum yield of $c a .51 \%$ achieved aller $8 \mathrm{~h}$ (Fig. S2 in the ESI†). The 
liquid sonication in other organic solvents such as acetone, tetrahydrofuran, and $N, N$-dimethylformamide also gave quite a high yield of $\mathrm{Fe}_{0.5} \mathrm{Co} 0.5 \mathrm{Pc}-\mathrm{CPNSs}$ (Fig. S2 in the ESI $\dagger$ ), suggesting the generality of the fabrication strategy.

The successful exfoliation of the bulk $\mathrm{Fe}_{0.5} \mathrm{Co}_{0.5} \mathrm{Pc}-\mathrm{CP}$ material into ultrathin $\mathrm{Fe}_{0.5} \mathrm{Co} 0.5 \mathrm{Pc}-\mathrm{CP}$ NSs is $\square$ rstly evidenced by the observation of a clear Tyndall effect when a green laser went through the suspension obtained a? tion process (inset in Fig. 1a). The transmission electron microscopy (TEM) image reveals a graphene-like structure of transparent $\mathrm{Fe}_{0.5} \mathrm{Co}_{0.5} \mathrm{Pc}-\mathrm{CP}$ NSs with a lateral size of several hundred nanometers (Fig. 1a), further con $\square$ rming the formation of ultrathin Fe0.5Co0.5Pc-CP NSs. The thickness of the $\mathrm{Fe}_{0.5} \mathrm{Co}_{0.5} \mathrm{Pc}-\mathrm{CPNSs}$ was measured by atomic force microscopy (AFM). It can be seen in Fig. $1 \mathrm{~b}$ and $\mathrm{c}$ that the Fe0.5Co0.5Pc-CP NSs possess a smooth surface with a uniform thickness of $1.05 \pm 0.05 \mathrm{~nm}$, corresponding to three layers. Nevertheless, no obvious lattice fringes are observed in aberration-corrected scanning transmission electron microscopy (AC STEM) images (Fig. 1d), which indicates that the amorphous nature of the CP individual layers originated from the less symmetrical isomers in $\mathrm{Fe}\left[\mathrm{Pc}(\mathrm{I})_{4}\right]$ and $\mathrm{Co}\left[\mathrm{Pc}(\text { ethynyl })_{4}\right]$. This is also supported by the fact that the selected area electron diffraction (SAED) pattern of the $\mathrm{Fe} 0.5 \mathrm{Co} .5 \mathrm{Pc}-\mathrm{CP}$ NSs shows broad halo rings (Fig. S3 in the ESI†). Moreover, from aberration-corrected high-angle annular dark- $\square$ eld STEM (AC HAADF-STEM) presented in Fig. 1e, bright dots (highlighted by red circles) are observed, which correspond to single $\mathrm{Fe} / \mathrm{Co}$ atoms located in $\mathrm{N}_{4}$-coordination sites of phthalocyanine ligands. In particular, the random dispersion of these $\mathrm{Fe} / \mathrm{Co}$ atoms also suggests the disordered framework of the $\mathrm{Fe} 0.5 \mathrm{Co} 0.5 \mathrm{Pc}-\mathrm{CP}$ NSs. Energy dispersive spectroscopy (EDS) and X-ray photoelectron spectroscopy (XPS) results indicate that the Fe $0.5 \mathrm{Co} 0.5 \mathrm{Pc}-\mathrm{CPNSs}$ are composed of C, N, O, I, Fe and Co, in accordance with the composition of the bulk $\mathrm{Fe}_{0.5} \mathrm{Co}_{0.5} \mathrm{Pc}-\mathrm{CP}$ material (Fig. S4 in the ESI†). ${ }^{49}$ The elemental mapping veri $\square$ es the homogenous surface distribution of $\mathrm{Co}, \mathrm{Fe}, \mathrm{C}$, and $\mathrm{N}$ throughout the whole Fe0.5Co0.5Pc-CP NSs (Fig. 1f). These analysis results, together with almost the same Fourier transform infrared, XPS, and solid-state UV-vis diffuse re $\square$ ectance spectra between bulk $\mathrm{Fe}_{0.5} \mathrm{Co} 0.5 \mathrm{Pc}-\mathrm{CP}$ and Fe $0.5 \mathrm{Co} 0.5 \mathrm{Pc}-\mathrm{CP} \mathrm{NSs}$, demonstrate that the chemical composition and bonding modes remain intact a? ? the ESI†). In addition, the Brunauer-Emmett-Teller (BET) surface area of $\mathrm{Fe}_{0.5} \mathrm{Co}_{0.5} \mathrm{Pc}-\mathrm{CP} \mathrm{NSs}$ is $80 \mathrm{~m}^{2} \mathrm{~g}^{-1}$ calculated from the $\mathrm{N}_{2}$ sorption isotherm at $77 \mathrm{~K}$, attributed to the mesopores formed by aggregation of nanosheets (Fig. S5 in the ESI†). This is signi $\square$ cantly larger than that of the bulk Fe ${ }_{.5} \mathrm{Co}_{0.5} \mathrm{Pc}-\mathrm{CP}$ (17 $\left.\mathrm{m}^{2} \mathrm{~g}^{-1}\right)$, suggesting that more active metal centers are exposed on the ultrathin nanosheets. The individual metal counterparts, FePc-CP NSs and CoPc-CP NSs, were also prepared under the same conditions with a yield of 42 and $60 \%$, respectively (Fig. S6-S9 in the ESI†), which show a similar shape, thickness (1.0 nm for CoPc-CP NSs and $3.2 \mathrm{~nm}$ for FePc-CP NSs), and surface area to the $\mathrm{Fe}_{0.5} \mathrm{Co} 0.5 \mathrm{Pc}-\mathrm{CPNSs}$. Additionally, the diyne linked Pc conjugated polymer $\mathrm{CoPc}-\mathrm{CP}-2$ fabricated through the alkyne-alkyne homocoupling reaction of $\mathrm{Co}[\mathrm{Pc}($ ethynyl) 4$]$ could also be exfoliated into ultrathin NSs with a yield ca. $40 \%$ (Fig. S10 in the ESI†). All the above facts also demonstrate the generality of the present fabrication strategy to exfoliate CPs to ultrathin conjugated polymer NSs.

It is worth noting again that the successful exfoliation of these Pc-based CP materials into 2D ultrathin NSs by liquid sonication is due to the weak interlayer interactions in bulk Pc-based CP materials, due to their intrinsic defected and highly disordered 2D networks. On the otherhand, if the CPs havean orderstacking structure and fewer defects, it is very hard to exfoliate them into
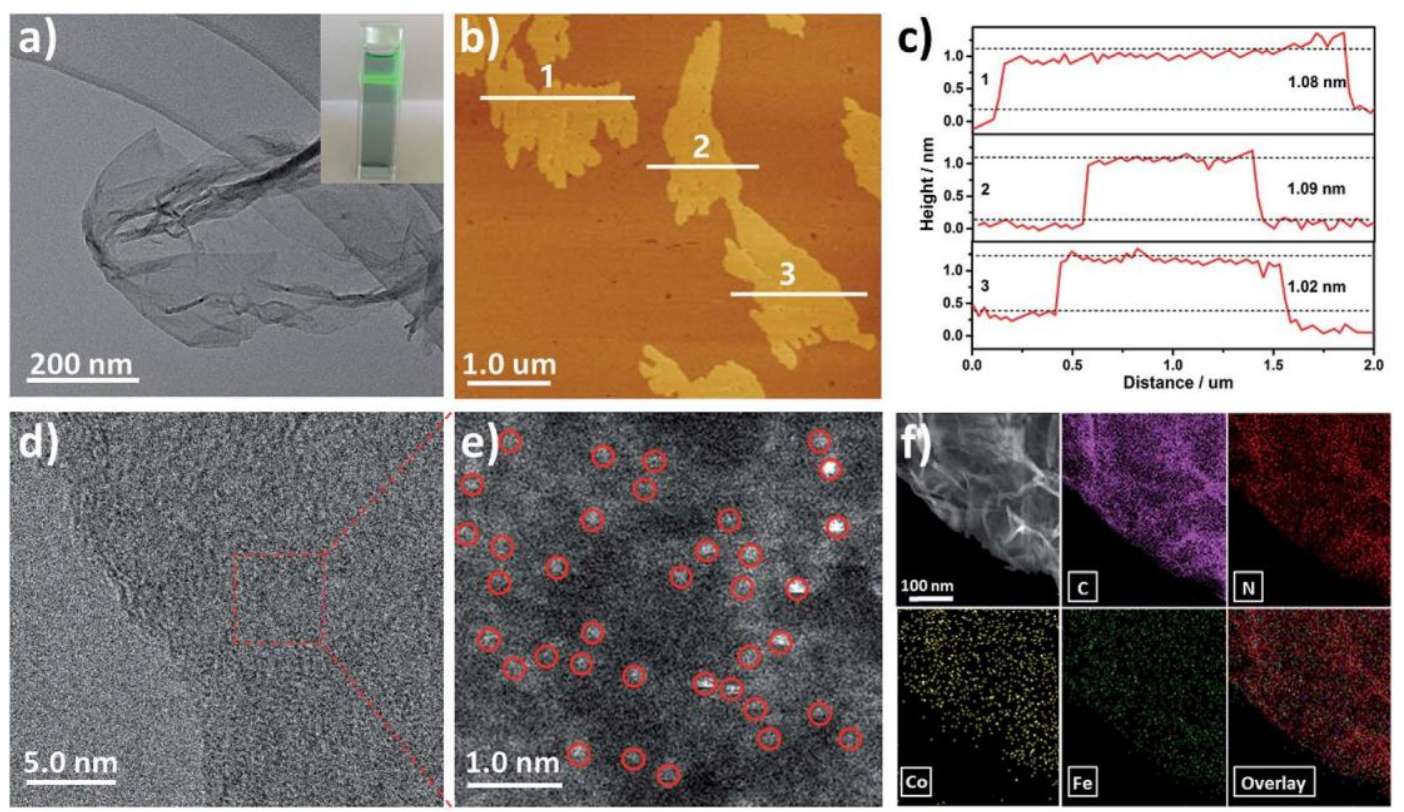

Fig. 1 (a) TEM image of $\mathrm{Fe}_{0.5} \mathrm{Co}_{0.5} \mathrm{Pc}-\mathrm{CP} \mathrm{NSs}$. Inset: Photograph of the Tyndall effect of the $\mathrm{Fe}_{0.5} \mathrm{Co}_{0.5} \mathrm{Pc}-\mathrm{CP}$ NS suspension. (b) AFM image and (c) the corresponding height profiles of $\mathrm{Fe}_{0.5} \mathrm{Co}_{0.5} \mathrm{Pc}-\mathrm{CPNSs}$. (d) ACSTEM image and (e) enlarged image of the $\mathrm{Fe}_{0.5} \mathrm{Co}_{0.5} \mathrm{Pc}-\mathrm{CP} \mathrm{NSs}$ (single Fe/ Co atoms are highlighted by red circles). (f) HAADF-STEM image and elemental mapping of $\mathrm{C}, \mathrm{N}, \mathrm{Co}$, and $\mathrm{Fe}$ of the $\mathrm{Fe}_{0.5} \mathrm{Co}_{0.5} \mathrm{Pc}_{\mathrm{C}} \mathrm{CP} \mathrm{NSs}$. 
ultrathin NSs. For example, a 2D layered Pc-based CP, denoted as FePc-CP-3, is synthesized from the reaction between 1,2,4,5-benzenetetranitrile and $\mathrm{FeCl}_{2}$ (see the ESI† for details). ${ }^{33,54}$ The ordered AA stacking crystal structure of FePc-CP-3 was con $\square$ rmed by powder X-ray diffraction (PXRD) and HRTEM (Fig. S1 1 b and c in the ESI†). In contrast to MPc-CPs and CoPc-CP-2, only a small amount of bulkFePc-CP-3 material $(<5 \%)$ was exfoliated into NSs with the thickness in a wide range a? ?er ultrasonic exfoliation for 8 $h$ in ethanol (Fig. S11d in the ESI†), because of the intense interlayer $\mathrm{p}-\mathrm{p}$ interaction.

\section{Preparation of the $\mathrm{Fe}_{0.5} \mathrm{Co}_{0.5} \mathrm{Pc}-\mathrm{CP} \mathrm{NS@G}$ heterostructure}

It has previously been reported that the bulk $\mathrm{Fe}_{0.5} \mathrm{Co} .5 \mathrm{Pc}-\mathrm{CP}$ material exhibits good ORR activity owing to the synergetic effect between the proximate Fe and Coions in the conjugated polymer. ${ }^{42}$ Normally, the ultrathin NSs are more active than the bulk counterpart attributed to the more exposed catalytic sites and easier mass transportation. Accordingly, it is reasonable to hypothesize that the ORR activity can be signi $\square$ cantly improved when coupling the ultrathin $\mathrm{Fe}_{0.5} \mathrm{Co} 0.5 \mathrm{Pc}-\mathrm{CP}$ NSs and graphene to fabricate the heterostructure Fe0.5Co0.5Pc-CP NS@G. The synthesis strategy of $\mathrm{Fe}_{0 .} \mathrm{Co}_{0 .} \mathrm{Pc}-\mathrm{CP} \mathrm{NS} @ \mathrm{G}$ is shown in Fig. 2a. Owing to the conjugated structure of both components, Fe0.5$\mathrm{Co}_{0.5} \mathrm{Pc}-\mathrm{CP}$ NSs and graphene NSs were easily hybridized together depending on effective interlayer $\mathrm{p}-\mathrm{p}$ interactions. It is directly observed by TEM (Fig. $2 \mathrm{~b}$ ) that the $\mathrm{Fe}_{0.5} \mathrm{Co} 0.5 \mathrm{Pc}-\mathrm{CP}$ NSs were assembled on the surface of graphene NSs. EDS mapping analysis indicates a coincident distribution of $\mathrm{Fe}, \mathrm{Co}$, and $\mathrm{N}$ throughout the exfoliated $\mathrm{Fe}_{0.5} \mathrm{Co}_{0.5} \mathrm{Pc}-\mathrm{CP}$ NSs on graphene NSs (Fig. 2b). Furthermore, XPS was also conducted to investigate the as- prepared heterostructure. As can be seen in Fig. S12, $†$ the XPS full survey of $\mathrm{Fe} 0.5 \mathrm{Co} .5 \mathrm{Pc}-\mathrm{CPNS} @ \mathrm{G}$ reveals the presence of $\mathrm{C}, \mathrm{N}$, $\mathrm{O}, \mathrm{I}, \mathrm{Fe}$, and Co elements, well consistent with the EDS results (Fig. S13in the ESI†). In the Fe 2 p spectrum, two peaks of Fe 2 $\mathrm{p}_{3} / 2$ and $\mathrm{Fe} 2 \mathrm{p}_{1 / 2}$ were observed at 709.0 and $722.9 \mathrm{eV}$ of Fe ${ }_{0.5} \mathrm{Co}_{0.5} \mathrm{Pc}-$ CP NS@G (Fig. 2d), while the Co 2p spectrum displayed the two peaks of Co 2 $\mathrm{p}_{3 / 2}$ and Co 2 $\mathrm{p}_{1 / 2}$ at 779.7 and $794.5 \mathrm{eV}$ (Fig. 2e), respectively. Interestingly, compared to the $\mathrm{Fe}_{0.5} \mathrm{Co}_{0.5} \mathrm{Pc}-\mathrm{CPNSs}$, the peaks of Fe 2p and Co 2p of Fe0.5Co0.5Pc-CP NS@G shi?to lower energy, indicating a strong interaction between $\mathrm{Fe} 0.5 \mathrm{Co} 0.5-$ Pc-CP NSs and graphene NSs in the as-prepared heterostructure. Generally, the decrease in binding energy reveals an enhanced electron screening effect because of the increase in electron density. These results suggest the charge transfer between the two components at the interface of $\mathrm{Fe}_{0.5} \mathrm{Co} 0.5 \mathrm{Pc}-\mathrm{CPNS} \mathrm{G}$, resulting in electron accumulation at the metal sites in $\mathrm{Fe}_{0.5} \mathrm{Co}_{0.5} \mathrm{Pc}-\mathrm{CP} \mathrm{NSs}$. To further demonstrate this point, density functional theory (DFT) calculations were carried out at the level of PBE/Lanl2DZ/3$21 \mathrm{G}$ (for C, H, and N atoms) using Gaussian 09 D.01. ${ }^{55-58}$ Fig. $2 \mathrm{f}$ shows the geometry of the fully relaxed Fe $0.5 \mathrm{Co} 0.5 \mathrm{Pc}-\mathrm{CP} \mathrm{NS} @ \mathrm{G}$ compositeas wellas the chargedensity differences. As shown, the electrons tended to redistribute around the metal sites a? assembling the $\mathrm{Fe}_{0.5} \mathrm{Co} 0.5 \mathrm{Pc}-\mathrm{CPNSs}$ and graphene NSs together, which favors to bind $\mathrm{O}_{2}$ molecules. This, in combination with the highly exposed active centers, suggests the optimized ORR performance of $\mathrm{Fe}_{0.5} \mathrm{Co} .5 \mathrm{Pc}-\mathrm{CPNS} @ \mathrm{G}$.

\section{ORR electrocatalytic activity}

TheORRproperties ofFe $0.5 \mathrm{Co} 0.5 \mathrm{Pc}-\mathrm{CPNS} @$ Gwere evaluated by steady-state linear sweep voltammetry (LSV) on a rotating disk
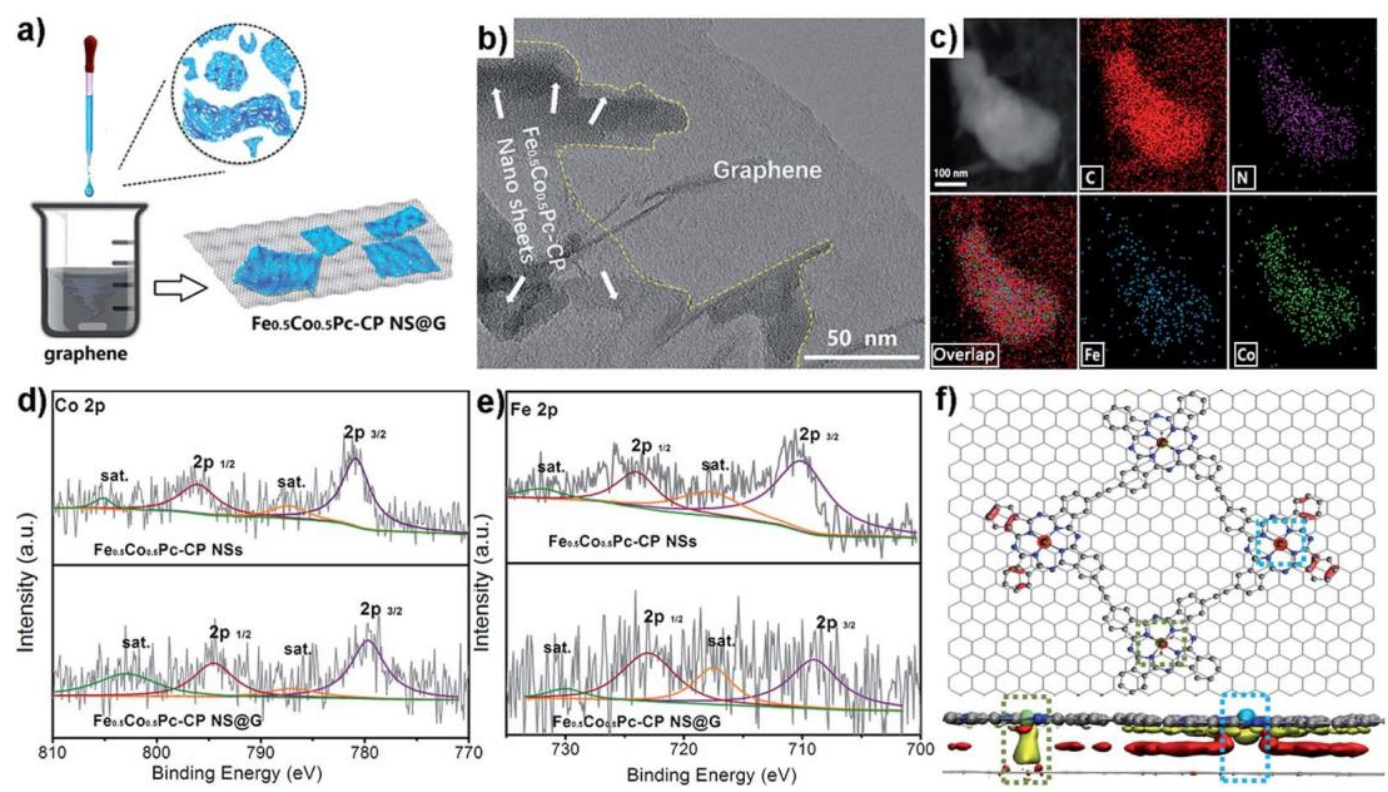

Fig. 2 (a) Schematic illustration of synthetic Fe $\mathrm{Fe}_{0.5} \mathrm{Co}_{0.5} \mathrm{Pc}-\mathrm{CP} \mathrm{NS} @ \mathrm{G}$. (b) TEM image of $\mathrm{Fe}_{0.5} \mathrm{Co}_{0.5} \mathrm{Pc}-\mathrm{CP}$ NS@G. (c) HAADF-STEM image and corresponding elemental mapping of $\mathrm{C}, \mathrm{N}$, Co, and $\mathrm{Fe}$. (d, e) XPS spectra of Fe $2 \mathrm{p}$ and $\mathrm{Co} 2 \mathrm{p}$ of $\mathrm{Fe}_{0.5} \mathrm{Co}_{0.5} \mathrm{Pc}_{\mathrm{CP}} \mathrm{CPSs}$ and $\mathrm{Fe} \mathrm{e}_{0.5} \mathrm{Co}_{0.5} \mathrm{Pc}-\mathrm{CP} \mathrm{NS} @ \mathrm{G}$. (f) The top and side views of the charge density difference plot for the interfaces between $\mathrm{Fe}_{0.5} \mathrm{Co}_{0.5} \mathrm{Pc}-\mathrm{CP} \mathrm{NSs}$ and graphene. Yellow and red isosurfaces indicate charge accumulation and depletion, respectively, with an isosurface value of 0.002 e $\AA^{-3}$. For clarity, the graphene and $\mathrm{Fe}_{0.5} \mathrm{Co}_{0.5} \mathrm{Pc}-\mathrm{CP} \mathrm{NSs}$ are shown in stick and ball-and-stick models, respectively. Gray, blue, ice blue, and light green balls represent $\mathrm{C}$, N, Fe, and Co atoms in $\mathrm{Fe}_{0.5} \mathrm{Co}_{0.5} \mathrm{Pc}-\mathrm{CP} \mathrm{NSs}$, respectively. 
electrode (RDE) with a rotation speed of $1600 \mathrm{rpm}$ in $\mathrm{O}_{2}$-saturated $0.1 \mathrm{M} \mathrm{KOH}$ solution. For the purpose of illustrating the key factors that contributed to the ORR performance of $\mathrm{Fe} 0.5 \mathrm{Co} 0.5 \mathrm{Pc}-\mathrm{CP} \mathrm{NS} @ \mathrm{G}$, the electrocatalytic properties of heterostructures with different contents were measured (Fig. S14 in the ESI†). As can be seen, $\mathrm{Fe}_{0.5} \mathrm{Co} 0.5 \mathrm{Pc}-\mathrm{CP} @ \mathrm{G}$ with a ratio between Fe0.5 Co0.5Pc-CP NSs and G of $2: 1$ exhibits the best catalytic activity. For comparison, the LSV curves of the composite of bulk Fe0.5Co0.5Pc-CP and graphene $(2: 1)$ (denoted as $\mathrm{Fe}_{0.5} \mathrm{Co}_{0.5} \mathrm{Pc}-\mathrm{CP} \& \mathrm{G}$ ) as well as commercial $\mathrm{Pt} / \mathrm{C}$ $(20 \mathrm{wt} \%)$ were also recorded. As shown in Fig. 3a, Fe0.5Co0.5Pc-CP NS@G (the ratio between $\mathrm{Fe}_{0.5} \mathrm{Co}_{0.5} \mathrm{Pc}-\mathrm{CP}$ NSs and G is 2 : 1) exhibited an $E_{\text {onset }}$ of $1006 \mathrm{mV} v s$. RHE and an $E_{1 / 2}$ of $927 \mathrm{mV}$ vs. RHE, obviously superior to $\mathrm{Fe} 0.5 \mathrm{Co} .5 \mathrm{Pc}-\mathrm{CP} \& \mathrm{G}$ ( $E_{\text {onset }} 1 / 4954 \mathrm{mV} v s$. RHE and $E_{1 / 2}{ }^{1 / 4} 855 \mathrm{mV} v s$. RHE). Remarkably, with a similar onset potential, the $E_{1 / 2}$ of $\mathrm{Fe} 0.5^{-}$ Co0.5Pc-CP NS@G is $83 \mathrm{mV}$ more positive than that of commercial Pt/C (20 wt\%) ( $E_{1 / 2} 1 \frac{1}{4} 844 \mathrm{mV} v s$. RHE), outperforming most of the state-of-the-art ORR catalysts reported to date in an alkaline medium (see Table $\mathrm{S} 1$ in the ESI + ). The electrochemically active surface areas (ECSAs) and mass activity of $\mathrm{Fe}_{0.5} \mathrm{Co} 0.5 \mathrm{Pc}-\mathrm{CPNS} @ \mathrm{G}$ and $\mathrm{Fe}_{0.5} \mathrm{Co}_{0.5} \mathrm{Pc}-\mathrm{CP} @ \mathrm{G}$ were also determined to further evaluate their performance. $\mathrm{Fe}_{0.5-}$ Co0.5Pc-CP NS@G shows an ECSA of $159 \mathrm{~cm}^{2}$, signi $\square$ cantly
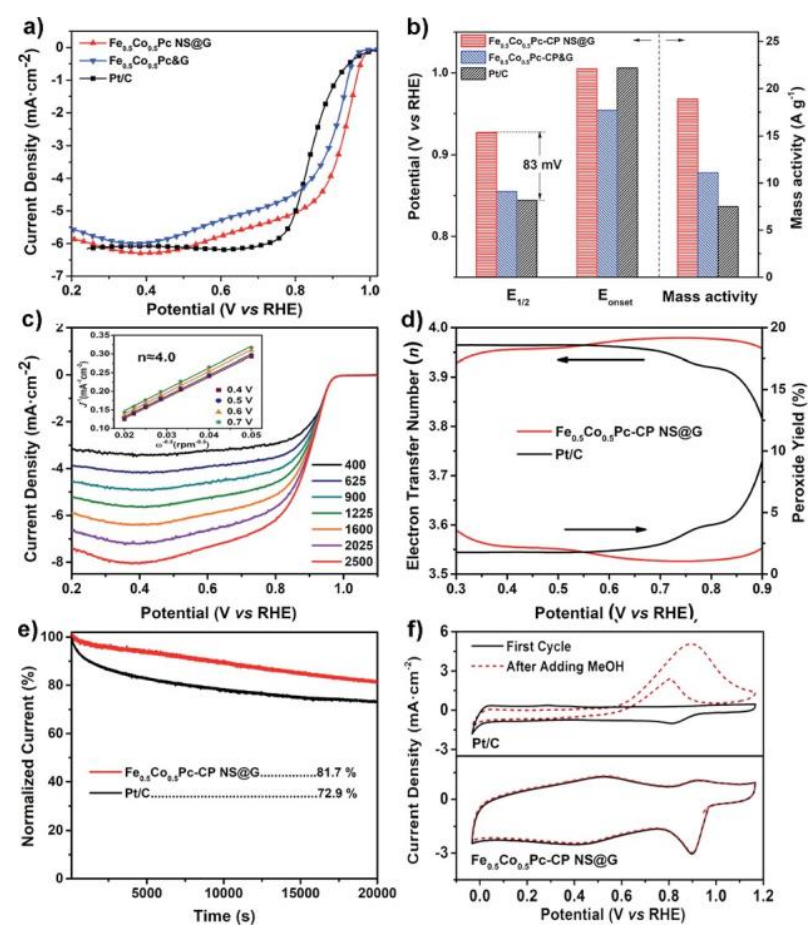

Fig. 3 (a) LSV curves of $\mathrm{Fe}_{0.5} \mathrm{Co}_{0.5} \mathrm{Pc}-\mathrm{CP} \mathrm{NS@G}, \mathrm{Fe}_{0.5} \mathrm{Co}_{0.5} \mathrm{Pc}-\mathrm{CP} \& \mathrm{G}$, and $\mathrm{Pt} / \mathrm{C}(20 \%)$ measured in $\mathrm{O}_{2}$-saturated $0.1 \mathrm{M} \mathrm{KOH}$ solution. (b)

Onset potential, half-wave potential and mass activity comparisons of $\mathrm{Fe}_{0.5} \mathrm{Co}_{0.5} \mathrm{Pc}-\mathrm{CP} \mathrm{NS} @ \mathrm{G}, \mathrm{Fe}_{0.5} \mathrm{Co}_{0.5} \mathrm{Pc}-\mathrm{CP} \& \mathrm{G}$ and Pt/C (20\%). (c) LSV curves at different rotation speeds of $\mathrm{Fe}_{0.5} \mathrm{Co}_{0.5} \mathrm{Pc}-\mathrm{CP} \mathrm{NS@G}$. The inset shows $\mathrm{K}-\mathrm{L}$ plots. (d) $\mathrm{H}_{2} \mathrm{O}_{2}$ yield and electron transfer number of $\mathrm{Fe}_{0.5} \mathrm{Co}_{0.5} \mathrm{Pc}-\mathrm{CP} \& \mathrm{G}$ and $\mathrm{Pt} / \mathrm{C}(20 \%)$. (e) Amperometric $i-t$ curves of $\mathrm{Fe}_{0.5} \mathrm{Co}_{0.5} \mathrm{Pc}-\mathrm{CP} \mathrm{NS} @ \mathrm{G}$ and $\mathrm{Pt} / \mathrm{C}(20 \%)$ under a rotation speed of 1600 rpm. (f) Methanol tolerance test for $\mathrm{Fe}_{0.5} \mathrm{Co}_{0.5} \mathrm{Pc}-\mathrm{CP} \mathrm{NS} @ \mathrm{G}$ and $\mathrm{Pt} / \mathrm{C}(20 \%)$. higher than that of $\mathrm{Fe}_{0.5} \mathrm{Co} 0.5 \mathrm{Pc}-\mathrm{CP} \& \mathrm{G}, 90 \mathrm{~cm}^{2}$ (Fig. S15 in the ESI†). The mass activity and turnover frequency of Fe0.5Co0.5Pc-CP NS@G are determined to be $18.9 \mathrm{~A} \mathrm{~g}^{-1}$ and $42.5 \mathrm{~s}^{-1}$ at $0.9 \mathrm{~V} v s$. RHE (Fig. 3b), respectively, which are signi $\square$ cantly higher than those of $\mathrm{Fe}_{0.5} \mathrm{Co}_{0.5} \mathrm{Pc}-\mathrm{CP} \& \mathrm{G}\left(11.1 \mathrm{~A} \mathrm{~g}^{-1}\right.$ and 28.7 $\mathrm{s}^{-1}$ ) and $\mathrm{Pt} / \mathrm{C}(20 \mathrm{wt} \%)\left(7.5 \mathrm{~A} \mathrm{~g}^{-1}\right.$ and $\left.1.2 \mathrm{~s}^{-1}\right)$, and comparable with the best values of Pt-free catalysts reported so far. ${ }^{42,59-66}$ These results coincide well with our expectation that $\mathrm{Fe}_{0.5-}$ Co0.5Pc-CP NS@G would show an enhanced ORR performance. The high ORR catalytic activity of $\mathrm{Fe}_{0.5} \mathrm{Co} 0.5 \mathrm{Pc}-\mathrm{CP}$ NS@G was further revealed by the catalytic selectivity. The

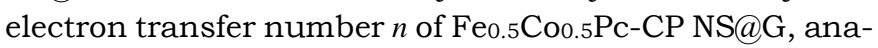
lysed based on the RDE measurements at different rotating speeds according to the Koutecky-Levich $(\mathrm{K}-\mathrm{L})$ equation, was ca. 4 at $0.4-0.7 \mathrm{~V} v$ s. RHE (Fig. 3c), indicating that the ORR at the $\mathrm{Fe}_{0.5} \mathrm{Co} 0.5 \mathrm{Pc}-\mathrm{CP} \mathrm{NS} @ \mathrm{G}$ electrode proceeds via a $4 \mathrm{e}^{-}$ reduction pathway. Rotation ring-disk electrode (RRDE) measurements were further carried out to determine the electron transfer number $n$ and monitor the generation of peroxide. It can be seen in Fig. 3d that $n$ was calculated to be over 3.9 at $0.3-0.9 \mathrm{~V} v$ s. RHE with a peroxide yield below $5 \%$, con $\square \mathrm{rming}$ the $4 \mathrm{e}^{-}$reduction pathway over $\mathrm{Fe}_{0.5} \mathrm{Co}_{0.5} \mathrm{Pc}-\mathrm{CP}$ NS@G. Besides the high ORR activity, the amperometric $i-t$ test revealed that the stability of Fe0.5Co0.5Pc-CP NS@G is superior to that of $\mathrm{Pt} / \mathrm{C}(20 \mathrm{wt} \%$ ) (Fig. 3e). Furthermore, the XPS spectra of Fe0.5Co0.5Pc-CP NS@G were recorded aler the $i-t$ test, which were almost unchanged, con $\square$ rming its high stability (see Fig. S16 in the ESI†). Moreover, Fe0.5Co0.5Pc-CP NS@G exhibits more excellent tolerance for methanol compared to $\mathrm{Pt} / \mathrm{C}$ (20 wt\%) (Fig. 3f). These results make

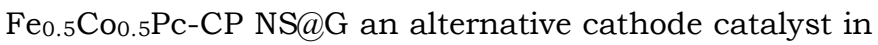
methanol fuel cells and metal-air batteries.

\section{Zn-air batteries}

Inspired by the notable half-cell performance of $\mathrm{Fe} 0.5 \mathrm{Co} 0.5 \mathrm{Pc}-$ CP NS@G in the ORR, this catalyst was further utilized as a cathode to evaluate the full-cell application in $\mathrm{Zn}$-air batteries under practical conditions (Fig. 4a). For the purpose of comparison, $\mathrm{Pt} / \mathrm{C}(20 \mathrm{wt} \%)$ was also integrated into a $\mathrm{Zn}$-air battery. As shown in Fig. 4b, the discharge polarization and power density plots of the Fe0.5Co0.5Pc-CP NS@G Zn-air battery show an open circuit voltage of $1.34 \mathrm{~V}$ and a maximum power density of $c a .180 \mathrm{~mW} \mathrm{~cm}-2$ at a current density of 283 $\mathrm{mA} \mathrm{cm}{ }^{-2}$, which are better than those of Pt/C (20 wt\%) (with an open circuit voltage of $1.33 \mathrm{~V}$ and a peak power density of ca. $152 \mathrm{~mW} \mathrm{~cm}^{-2}$ ). In addition, the $\mathrm{Fe}_{0.5} \mathrm{Co}_{0.5} \mathrm{Pc}-\mathrm{CP} \mathrm{NS} @ \mathrm{G} \mathrm{Zn}-$ air battery exhibits stable discharge voltage at a current density of $10 \mathrm{~mA} \mathrm{~cm}^{-2}$, comparable to that of $\mathrm{Pt} / \mathrm{C}(20 \mathrm{wt} \%)$

(Fig. 4c). To further broaden the application of $\mathrm{Fe}_{0.5} \mathrm{Co}_{0.5} \mathrm{Pc}-$

CP NS@G, a rechargeable Zn-air battery was fabricated with a mixture of Fe0.5Co0.5Pc-CP NS@G and RuO (a benchmark electrocatalyst for the oxygen evolution reaction) $(1: 1)$ as the cathode. This rechargeable $\mathrm{Zn}$-air battery exhibits very similar discharge polarization and power density plots to the

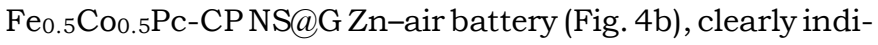
cating the dominant contribution of $\mathrm{Fe}_{0.5} \mathrm{Co}_{0.5} \mathrm{Pc}-\mathrm{CP} \mathrm{NS} @ \mathrm{G}$ to 

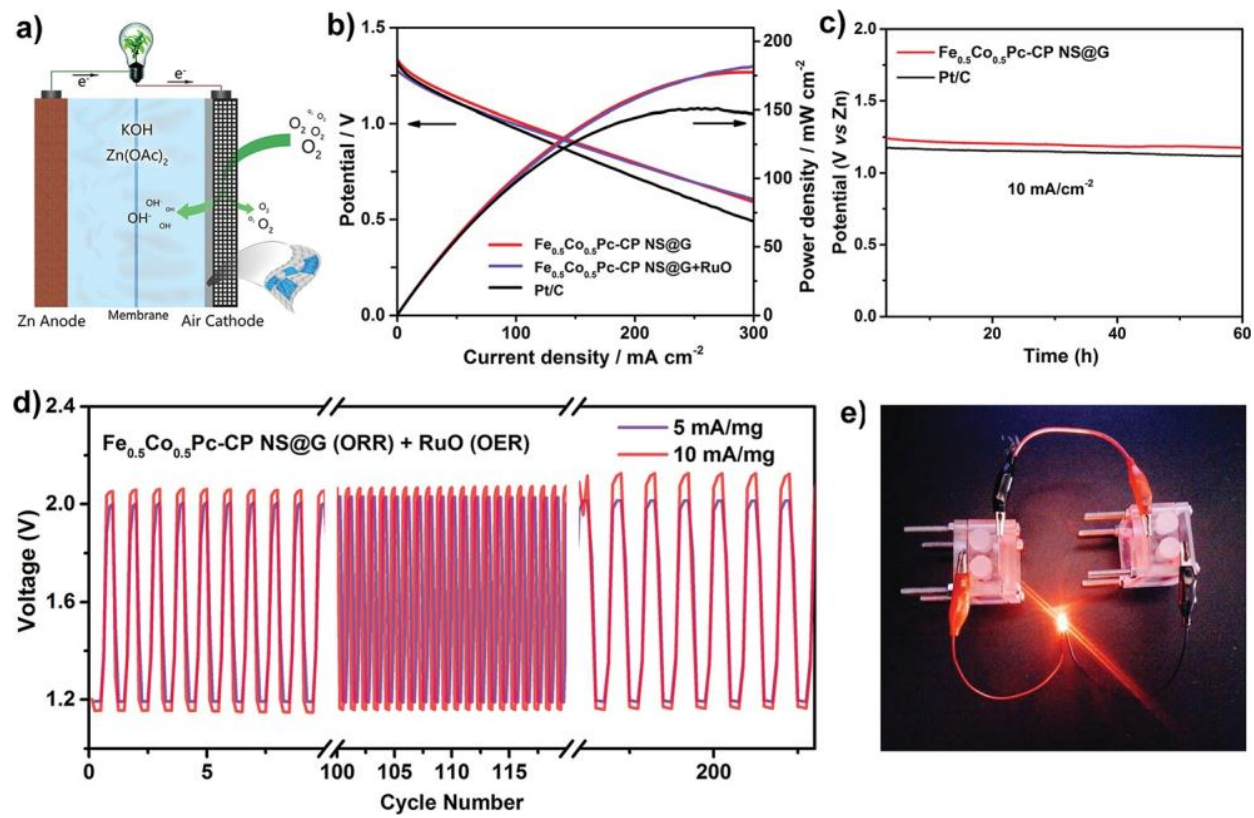

Fig. 4 (a) Schematic of the Zn-air battery. (b) The discharge polarization plots and power density curves of the Zn-air batteries. (c) Discharge plots of the $\mathrm{Zn}$-air batteries with $\mathrm{Fe}_{0.5} \mathrm{Co}_{0.5} \mathrm{Pc}$-CP NS@G as well as commercial Pt/C (20\%) as cathode catalysts at a current density of $10 \mathrm{~mA}$ cm ${ }^{-2}$. (d) The discharge and charge voltage profiles of the $\mathrm{Zn}$-air batteries with a mixture of $\mathrm{Fe}_{0.5} \mathrm{Co}_{0.5} \mathrm{Pc}-\mathrm{CP} \mathrm{NS} @ \mathrm{G}$ and RuO (1:1) as the cathode at current densities of 5 and $10 \mathrm{~mA} \mathrm{mg}^{-1}$. (e) Photographs of a LED light $(\mathrm{Z} 2 \mathrm{~V})$ powered by two zinc-air batteries with a mixture of $\mathrm{Fe}_{0.5} \mathrm{Co}_{0.5} \mathrm{Pc}$ CP NS@G and RuO as the cathode in series.

the ORR activity in the cathode of the rechargeable $\mathrm{Zn}$-air battery. Moreover, long-term cycling tests at current densities of 5 and $10 \mathrm{~mA} \mathrm{~cm}^{-1}$ reveal the lack of obvious change of discharge voltage over 200 cycles (Fig. 4d). Additionally, two rechargeable $\mathrm{Zn}$-air batteries in series could provide a high enough open circuit voltage to power a light-emitting diode (LED) light with a rated voltage of $\mathbf{Z 2} \mathrm{V}$ (Fig. 4e). These results disclose the great potential of the Fe0.5Co0.5Pc-CP NS@G composite in $\mathrm{Zn}$-air battery applications.

\section{Conclusions}

We report the efficient exfoliation of a series of conjugated ultrathin MPc-CP NSs (M 1 1/4 Fe, Co, Fe $0.5 \mathrm{Co} .5$ ) from their bulk counterparts, owing to the introduction of defects and disorders into the individual layers, which enable diminished interlayer overlapping and weakened interlayer $p-p$ stacking. The ultrathin MPc-CP NSs possess a smooth surface with a uniform thickness and alateral size of several hundred nanometers. The as-prepared bimetallic Fe0.5 $\mathrm{Co} .5 \mathrm{Pc}-\mathrm{CP}$ NSs can be used to fabricate a heterostructure $\mathrm{Fe}_{0.5} \mathrm{Co}_{0.5} \mathrm{Pc}-\mathrm{CP} \mathrm{NS} @ \mathrm{G}$ with graphene NSs as a high-performance ORR catalyst with an onset potential of $1006 \mathrm{mV}$ and a half-wave potential of $927 \mathrm{mV}$ in $0.1 \mathrm{M} \mathrm{KOH}$, outperforming most of the state-of-the-art ORR catalysts reported so far in an alkaline medium. Its excellent ORR activity has also been demonstrated by the good performance of a $Z n$-air battery device, with an open circuit voltage of $1.34 \mathrm{~V}$ and a peak power density of $\boldsymbol{Z} 180 \mathrm{~mW} \mathrm{~cm}^{-2}$. This work is surely helpful for further design and synthesis of other ultrathin 2D CP/COF NSs with a tunable conjugated electronic and geometric structure, which might have various promising applications in electronics and energy-related $\square$ elds.

\section{Experimental section}

General remarks

All reagents and solvents were of reagent grade and used as received. $\mathrm{Fe}_{0 .} \mathrm{Co}_{0.5} \mathrm{Pc}-\mathrm{CP}$, CoPc- $\mathrm{CP}, \mathrm{FePc}-\mathrm{CP}$, and $\mathrm{CoPc}-\mathrm{CP}-2$ were synthesized by using reported procedures. ${ }^{42}$

Preparation of Fe $0.5 \mathrm{Co} 0.5 \mathrm{Pc}-\mathrm{CP}$ NSs, FePc-CP NSs, and CoPc-CP NSs

The NSs were obtained by exfoliation of bulk MPc-CP materials via a simple sonication procedure. In a typical experiment, $\mathrm{Fe}_{0.5} \mathrm{Co} 0.5 \mathrm{Pc}-\mathrm{CP}$ powder $(20 \mathrm{mg}$ ) was dispersed in ethanol (60 $\mathrm{mL})$. The suspension was then sonicated in an ultrasonication bath (KQ-500DE, $40 \mathrm{kHz}, 500 \mathrm{~W}$ ) for $8 \mathrm{~h}$ under room temperature. The resulting suspension was centrifuged at $2000 \mathrm{rpm}$ for $5 \mathrm{~min}$ to remove the unexfoliated bulk $\mathrm{Fe}_{0.5} \mathrm{Co} 0 .{ }_{5} \mathrm{Pc}-\mathrm{CP}$. The yield is calculated by measuring the remaining weight of collected unexfoliated bulk $\mathrm{Fe}_{0 .} \mathrm{Co}_{0.5} \mathrm{Pc}-\mathrm{CP}$ and comparing it to the weight of original crystals before sonication. As a result, the measured yield is $51 \%$. FePc-CP NSs, CoPc-CP NSs, and CoPcCP-2 NSs were prepared by the same procedure with a yield of $42 \%, 60 \%$, and $40 \%$, respectively.

\section{Preparation of $\mathrm{Fe}_{0.5} \mathrm{Co}_{0.5} \mathrm{Pc}-\mathrm{CP} \mathrm{NS@G}$}

Typically, a designed volume $\left(2.0 \mathrm{mg} \mathrm{mL}^{-1}\right)$ of the exfoliated $\mathrm{Fe}_{0.5} \mathrm{Co} 0.5 \mathrm{Pc}-\mathrm{CPNSs}$ was added drop by dropinto a graphene NS suspension with a concentration of $1.0 \mathrm{mg} \mathrm{mL}^{-1}$ under 
continuous stirring for $8 \mathrm{~h}$ at $70^{\circ} \mathrm{C}$. The $\square$ occulated product was separated by centrifugation. The weight ratios of $\mathrm{Fe} 0.5 \mathrm{Co} 0.5 \mathrm{Pc}-$ CP NSs and $G$ were controlled as $1: 1,2: 1,4: 1$, and $8: 1$.

Preparation of $\mathrm{Fe}_{0.5} \mathrm{Co}_{0.5} \mathrm{Pc}-\mathrm{CP} \& \mathrm{G}$

$\mathrm{Fe}_{0 .} \mathrm{Co}_{0.5} \mathrm{Pc}-\mathrm{CP} \& \mathrm{G}$ was prepared by the same procedure as

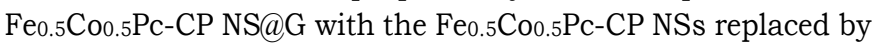
bulk Fe $0.5 \mathrm{Co0} .5 \mathrm{Pc}-\mathrm{CP}$.

\section{Conflicts of interest}

There are no con $\square$ icts to declare.

\section{Acknowledgements}

Financial support from the Natural Science Foundation of China (No. 21631003, 21671017, and 21871024), the Fundamental Research Funds for the Central Universities (No. FRFBD-17-016A), and the University of Science and Technology Beijing is gratefully acknowledged.

\section{References}

1 S.-Y. Ding and W. Wang, Chem. Soc. Rev., 2013, 20, 548-568. 2 H. Furukawa and O. M. Yaghi, J. Am. Chem. Soc., 2009, 131, 8875-8883.

3 Y. Xu, S. Jin, H. Xu, A. Nagai and D. Jiang, Chem. Soc. Rev., 2013, 42, 8012-8031.

4 X. Ding and B. Han, Angew. Chem., Int. Ed., 2015, 54, 6536-6539.

5 K. Wang, D. Qi, Y. Li, T. Wang, H. Liu and J. Jiang, Coord. Chem. Rev., 2019, 378, 188-206.

6 G. Li, Y. Li, H. Liu, Y. Guo, Y. Li and D. Zhu, Chem. Commun., 2010, 46, 3256-3258.

7 Y.Xue, Y.Li, J.Zhang, Z. Liu and Y.Zhao, Sci. China: Chem., 2018, 61, 765-786.

8 C. Huang, Y. Li, N. Wang, Y. Xue, Z. Zuo, H. Liu and Y. Li, Chem. Rev., 2018, 118, 7744-7803.

9 H. Yu, Y. Xue, L. Hui, C. Zhang, Y. Li, Z. Zuo, Y. Zhao, Z. Li and Y. Li, Adv. Mater., 2018, 30, 1707082.

10 Y.Xue, B. Huang, Y. Yi, Y. Guo, Z.Zuo, Y. Li, Z. Jia, H. Liu and Y. Li, Nat. Commun., 2018, 9, 1-10.

11 Z. Kang, Y. Peng, Y. Qian, D. Yuan, M. A. Addicoat, T. Heine, Z. Hu, L. Tee, Z. Guo and D. Zhao, Chem. Mater., 2016, 28, 1277-1285.

12 S. Keskin, J. Phys. Chem. C, 2012, 116, 1772-1779.

13 R. Dong, Z.Zheng, X.Zhu, J.Zhang, X. Feng, M. Pfeffermann and H. Liang, Angew. Chem., Int. Ed., 2015, 54, 12058-12063.

14 Z. Xiang, D. Cao, L. Huang, J. Shui, M. Wang and L. Dai, Adv. Mater., 2014, 26, 3315-3320.

15 J.Zhang, F. Guo and X. Wang, Adv. Funct. Mater., 2013, 23, 3008-3014.

16 Q. Xu, Y. Tang, X. Zhang, Y. Oshima, Q. H. Chen and D. Jiang, Adv. Mater., 2018, 30, 1706330.

17 M.Zhang, G. Feng, Z. Song, Y.-P.Zhou, H.-Y. Chao, D. Yuan, T. T. Y. Tan, Z. Guo, Z. Hu, B. Z. Tang, B. Liu and D. Zhao, J. Am. Chem. Soc., 2014, 136, 7241-7244.
18 H. Xu, J. Gao, X. Qian, J. Wang, H. He, Y. Cui, Y. Yang, Z. Wang and G. Qian, J. Mater. Chem. A, 2016, 4, 1090010905.

19 Y. Gao, H. L. Yip, K. S. Chen, K. M. O'Malley, O. Acton, Y. Sun, G. Ting, H. Z. Chen and A. K. Y. Jen, Adv. Mater., 2011, 23, 1903-1908.

20 J. W. Colson, A. R. Woll, A. Mukherjee, M. P. Levendorf, E. L. Spitler, V. B. Shields, M. G. Spencer, J. Park and W. R. Dichtel, Science, 2011, 332, 228-231.

21 J. Dugay, M. Gimenez-Marques, T. Kozlova, H. W. Zandbergen, E. Coronado and H. S. J. van der Zant, Adv. Mater., 2015, 27, 1288-1293.

22 S. Zhao, Y. Wang, J. Dong, C.-T. He, H. Yin, P. An, K. Zhao, X. Zhang, C. Gao, L. Zhang, J. Lv, J. Wang, J. Zhang, A. M. Khattak, N. Ali Khan, Z. Wei, J. Zhang, S. Liu, H. Zhao and Z. Tang, Nat. Energy, 2016, 1, 16184.

23 Y. Ma, B. Li and S. Yang, Mater. Chem. Front., 2018, 2, 456467.

24 M. Osada and T. Sasaki, Adv. Mater., 2012, 24, 210-228.

25 X. Huang, C. Tan, Z. Yin and H. Zhang, Adv. Mater., 2014, 26, 2185-2204.

26 H. Sahabudeen, H. Y. Qi, B. A. Glatz, D. Tranca, R. H. Dong, Y. Hou, T. Zhang, C. Kuttner, T. Lehnert, G. Seifert, U. Kaiser, A. Fery, Z. K. Zheng and X. L. Feng, Nat. Commun., 2016, 7, 13461.

27 Q. Lu, Y. Yu, Q. Ma, B. Chen and H.Zhang, Adv. Mater., 2016, 28, 1917-1933.

28 C. Tan, X. Cao, X.-J. Wu, Q. He, J. Yang, X. Zhang, J. Chen, W. Zhao, S. Han, G.-H. Nam, M. Sindoro and H. Zhang, Chem. Rev., 2017, 117, 6225-6331.

29 M. A. Lukowski, A. S. Daniel, F. Meng, A. Forticaux, L. Li and S. Jin, J. Am. Chem. Soc., 2013, 135, 10274-10277.

30 Y. Peng, Y. Huang, Y. Zhu, B. Chen, L. Wang, Z. Lai, Z. Zhang, M. Zhao, C. Tan, N. Yang, F. Shao, Y. Han and H. Zhang, J. Am. Chem. Soc., 2017, 139, 8698-8704.

31 N. P. Armitage, J. C. P. Gabriel and G. Gruner, J. Appl. Phys., 2004, 95, 3228-3230.

32 F. C. Krebs, Sol. Energy Mater. Sol. Cells, 2009, 93, 394-412.

33 H. Sirringhaus, T. Kawase, R. H. Friend, T. Shimoda, M. Inbasekaran, W. Wu and E. P. Woo, Science, 2000, 290, 2123-2126.

34 H. Minemawari, T. Yamada, H. Matsui, J. Y. Tsutsumi, S. Haas, R. Chiba, R. Kumai and T. Hasegawa, Nature, 2011, 475, 364-367.

35 S. Wang, Q. Wang, P. Shao, Y. Han, X. Gao, L. Ma, S. Yuan, X. Ma, J. Zhou, X. Feng and B. Wang, J. Am. Chem. Soc., 2017, 139, 4258-4261.

36 D. N. Bunckand W. R. Dichtel, J.Am. Chem. Soc., 2013, 135, 14952-14955.

37 S. Chandra, S. Kandambeth, B. P. Biswal, B. Lukose, S. M. Kunjir, M. Chaudhary, R. Babarao, T. Heine and R. Banerjee, J. Am. Chem. Soc., 2013, 135, 17853-17861.

38 S. Mitra, S. Kandambeth, B. P. Biswal, M. A. Khayum, C. K. Choudhury, M. Mehta, G. Kaur, S. Banerjee, A. Prabhune, S. Verma, S. Roy, U. K. Kharu and R. Banerjee, J. Am. Chem. Soc., 2016, 138, 2823-2828. 
39 S. Mitra, H. S. Sasmal, T. Kundu, S. Kandambeth, K. Math, D. D. Diaz and R. Banerjee, J. Am. Chem. Soc., 2017, 139, 4513-4520.

40 M. A. Khayum, S. Kandambeth, S. Mitra, S. B. Nair, A. Das, S. S. Nagane, R. Mukherjee and R. Banerjee, Angew. Chem., Int. Ed., 2016, 55, 15604-15608.

41 A. B. Marco, D. Cortizo-Lacalle, I. Perez-Miqueo, G. Valenti, A. Boni, J. Plas, K. Strutynski, S. De Feyter, F. Paolucci, M. Montes, A. N. Khlobystov, M. Melle-Franco and A. Mateo-Alonso, Angew. Chem., Int.Ed., 2017, 56, 6946-6951.

42 W. Liu, Y. Hou, H. Pan, W. Liu, D. Qi, K. Wang, J. Jiang and X. Yao, J. Mater. Chem. A, 2018, 6, 8349-8357.

43 Y. Chen, W. Cao, C. Wang, D. Qi, K. Wang and J. Jiang, Inorg. Chem., 2016, 55, 3151-3160.

44 P. Hobza and J. Šponer, Chem. Rev., 1999, 99, 3247-3276.

45 K. Wang, D. Qi, H. Wang, W. Cao, W. Li and J. Jiang, Chem.Eur. J., 2012, 18, 15948-15952.

46 T. D. Thanh, N. D. Chuong, H. V. Hien, T. Kshetri, L. H. Tuan, N. H. Kim and J. H. Lee, Prog. Mater. Sci., 2018, 96, 51-85.

47 Y.Jia, L.Zhang, G. Gao, H.Chen, B. Wang, J.Zhou, M. T. Soo, M. Hong, X. Yan, G. Qian, J. Zou, A. Du and X. Yao, $A d v$. Mater., 2017, 17, 1700017.

48 Y. Li, H. Liu, H. Wang, J. Qiu and X. Zhang, Chem. Sci., 2018, 9, 4132-4141.

49 A. B. Soliman, M. H. Hassan, T. N. Huan, A. A. Abugable, W. A. Elmehalmey, S. G. Karakalos, M. Tsotsalas, M. Heinle, M. Elbahri, M. Fontecave and M. H. Alkordi, ACS Catal., 2017, 7, 7847-7854.

50 A. B. Soliman, R. R. Haikal, A. A. Abugable, M. H. Hassan, S. G. Karakalos, P. J. Pellechia, H. H. Hassan, M. H. Yacoub and M. H. Alkordi, ACS Appl. Mater. Interfaces, 2017, 9, 27918-27926.

51 A. B. Soliman, R. R. Haikal, A. A. Abugableand M. H. Alkordi, J. Mater. Chem. A, 2017, 5, 1957-1961.
52 A. B. Soliman, M. H. Hassan, A. A. Abugable, S. G. Karakalos and M. H. Alkordi, ChemCatChem, 2017, 9, 2892.

53 M. Abel, S. Clair, O. Ourdjini, M. Mossoyan and L. Porte, J. Am. Chem. Soc., 2011, 133, 1203-1205.

54 Z. Honda, Y. Sakaguchi, M. Tashiro, M. Hagiwara, T. Kida, M. Sakai, T. Fukuda and N. Kamata, Appl. Phys. Lett., 2017, $110,133101$.

55 J. P. Perdew, K. Burke and M. Ernzerhof, Phys. Rev. Lett., 1996, 77, 3865-3868.

56 P. J. Hay and W. R. Wadt, J. Chem. Phys., 1985, 82, 270-283.

57 J. S. Binkley, J. A. Pople and W. J. Hehre, J. Am. Chem. Soc., 1980, 102, 939-947.

58 M. J. Frisch, et al.Gaussian 09, Revision D.01, Wallingford, CT, Gaussian Inc, 2013.

59 Y. Wang, Y. Lai, L. Song, Z. Zhou, J. Liu, Q. Wang, X. Yang, C. Chen, W. Shi and Y. Zheng, Angew. Chem., Int. Ed., 2015, 54, 9907-9910.

60 K. P. Singh, E. J. Bae and J. Yu, J. Am. Chem. Soc., 2015, 137, 3165-3168.

61 X. Wang, B. Wang, J. Zhong, F. Zhao, N. Han, W. Huang, M. Zeng, J. Fan and Y. Li, Nano Res., 2016, 9, 1497-1506.

62 L. Zhang, J. M. T. A. Fischer, Y. Jia, X. Yan, W. Xu, X. Wang, J. Chen, D. Yang, H. Liu, L. Zhuang, M. Hankel, D. J. Searles, K. Huang, S. Feng, C. L. Brown and X. Yao, J. Am. Chem. Soc., 2018, 140, 10757-10763.

63 U. I. Kramm, I. Herrmann-Geppert, J. Behrends, K. Lips, S. Fiechter and P. Bogdanoff, J. Am. Chem. Soc., 2016, 138, 635-640.

64 L. Zhang, T. Liu, N. Chen, Y. Jia, R. Cai, W. Theis, X. Yang, Y. Xia, D. Yang and X. Yao, J. Mater. Chem. A, 2018, 6, 18417-18425.

65 D. Li, Y. Jia, G. Chang, J. Chen, H. Liu, J. Wang, Y. Hu, Y. Xia, D. Yang and X. Yao, Chem, 2018, 4, 2345-2356.

66 W. Liu, K. Wang, C. Wang, W. Liu, H. Pan, Y. Xiang, D. Qi and J. Jiang, J. Mater. Chem. A, 2018, 6, 22851-22857. 